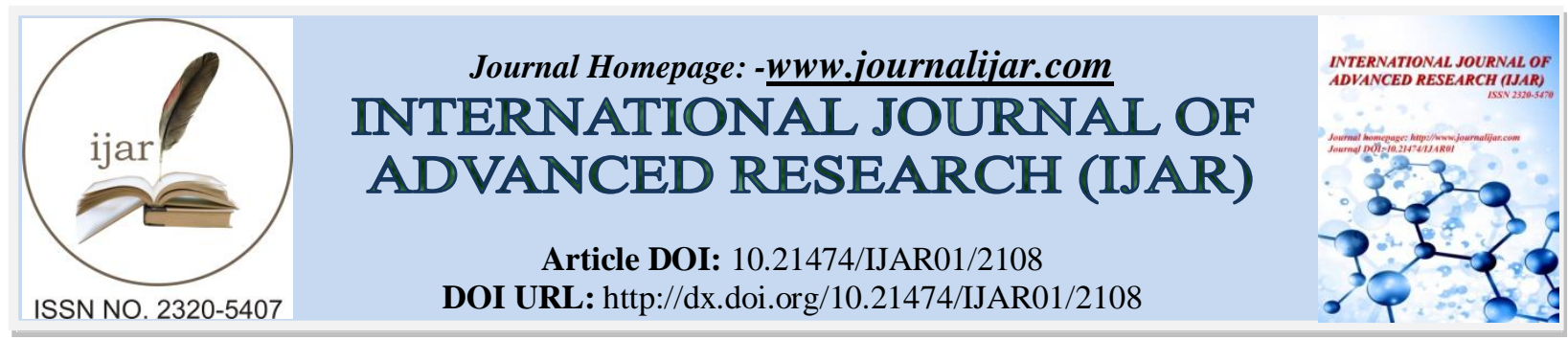

RESEARCH ARTICLE

\title{
ACHIEVEMENTS AND DEFICIENCIES IN DEVELOPMENT OF FARMERS' PROFESSIONAL COOPERATIVESIN SICHUAN PROVINCE.
}

\author{
MA Li ${ }^{1}{ }^{*}$ TANG Hong ${ }^{2}$, XIAO Yuejie ${ }^{1}$ and Liu Ying ${ }^{3}$. \\ 1. Master's student of land resources management, School of Management, Sichuan Agricultural University, \\ Chengdu, China. \\ 2. PHD of human geography, School of Management, Sichuan Agricultural University, Chengdu, China. \\ 3. Master's student of the Urban Planning and Policy Design, POLITECNICO Milano, Milano, Italy.
}

\section{Manuscript Info}

Manuscript History

Received: 25 September 2016

Final Accepted: 27 October 2016

Published: November 2016

Key words:-

Professional farmer's cooperatives, Income of farmers, Achievements and problems, Sichuan province.

\begin{abstract}
By focusing on farmers' professional cooperatives in Sichuan Province, this paper combines such methods as literature review, combination of qualitative and quantitative analysis, field study and summary of experience to offer an overview of general situation of development of Sichuan farmers' professional cooperatives, effectiveness in increasing farmers' incomes and development characteristics, analyze problems and deficiencies in development of farmers' professional cooperatives and propose suggestions for healthy development of farmers' professional cooperatives in the future, with the aim to provide references for further progress of rural reform experiments in Sichuan and establishment and development of farmers' professional cooperatives in other regions of China.
\end{abstract}

Copy Right, IJAR, 2016,. All rights reserved.

\section{Introduction:-}

Research Background:-

The current organizational form of agricultural production in rural areas in China is family based and organizational degree of farmers and production scale are both low, accompanied bysuch problems as excessive surplus rural labor force, poor risk resistance capability andbackward production conditions. Nonetheless, the establishment of farmers' professionalcooperatives can help eliminate such dispersed agricultural production units, integrate scattered peasant households and rural resources and break restrictions of household management of production, thus realizing largescale and intensive development of agricultural production.

In recent years, Chinese scholars has made extensive research on the development conditions(WANG Y,2012;SUN Y F, et al.,2012), problems (HUANG S Y, 2015;ZHENG D, et al., 2012; LIAO S L, et al., 2014), operating mechanisms, governance structure and new trends of farmers' professional cooperatives (LAN Y, et al., 2015; ZHANG L X, et al., 2015; ZHANG X S, 2009; HUO Z S, 2015). There are also scholars further researched on performance (CHEN G R,et al., 2014; ZHANGY, 2011), operation mode, influencing factors (WAN B R, 2010; ZHAO K, 2011), financing and other aspects of the cooperatives by adopting such methods as BSC (Xu X C, 2012; CUI B Y, 2015), analytic hierarchy process (AHP) and field survey (GUO H D, et al., 2009; HUANG Z H, 2012). Research on farmers' professional cooperatives is favorable for deepening agricultural management system reform.

Corresponding Author:-TANG Hong. Address:-PHD of human geography, School of Management, Sichuan Agricultural University, Chengdu, China. 


\section{Research Region Overview and Research Significance:-}

Sichuan Province is located in southwest China, the upper reaches of Yangtze River and covers a total area of $486,000 \mathrm{~km}^{2}$. With three planting patterns, namely, food crops, cash crops and other crops, and total planting area of 970 million hectare, Sichuan is a major agricultural province of China. Agriculture is the typical feature of western China and even the entire nation. Economic aggregate of Sichuan ranks $8^{\text {th }}$ in the nation and $1^{\text {st }}$ in western China. Value added of the first, second and tertiary industries of Sichuan in 2015 were respectively RMB367.73 billion, RMB1.42932 trillion and RMB1.21326 trillion. It can be seen that value added of the first industry is far behind that of the other two industries, so how to increase farmers' incomes is an issue worth studying. Consequently, research on development conditions and economic benefits of farmers' professional cooperatives in Sichuan has huge research significance for economic development of Sichuan Province and is typical for western China.

\section{General Situation of Development of Sichuan Famer's Professional Cooperatives:- Development scale and speed of Sichuan farmers' professional cooperatives:-}

According to statistics of Sichuan Provincial Agricultural Department, by the end of 2014, there were 48339 farmer cooperatives in Sichuan Province and those with business registration certificates reached 47329, with total investment amounting to RMB108.537 billion. Among them, national and provincial farmers' professional cooperatives respectively were 462 and 1030, accounting for $3.2 \%$ of all farmer cooperatives in Sichuan (Department of Agriculture, 2015) . Figure 1 shows changes in the number of farmers' professional cooperatives in Sichuan from 2007 to 2014. It can be seen from the figure that the number of farmers' professional cooperatives in Sichuan has been increasing since 2007, and the growth rate is increasing and the trend is obvious in recent two years.

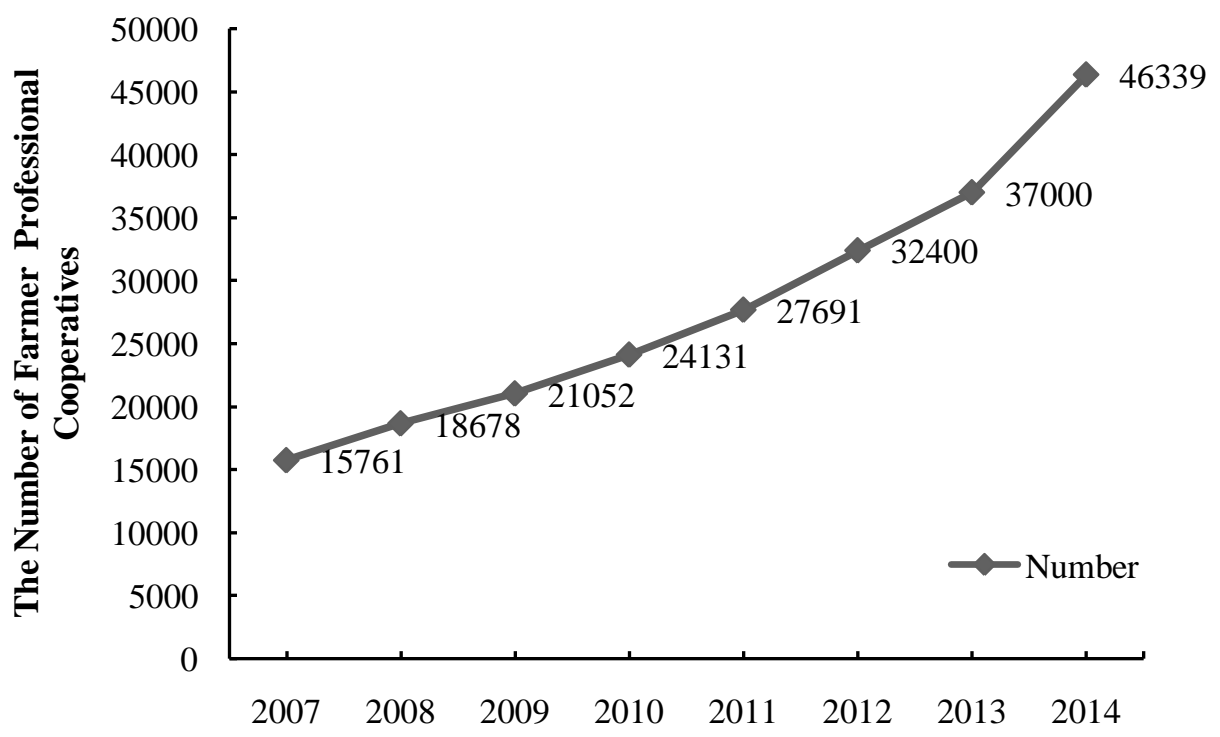

Figure 1:- The number of Farmer Professional Cooperatives in Sichuan provincefrom 2007 to 2014 years

As the members of cooperatives are constantly growing, farmer cooperative members in Sichuan reached 2.876 million households by the end of 2014, an increase of 386,000 households and a growth rate of $15.5 \%$ compared with the same period last year. Among them, there were 2.617 million farmer households, accounting for $91 \%$ of all members. 5.899 million farmer households were mobilized and $43.1 \%$ of the farmer households participated in production management of farmers' professional cooperatives. The various farmers' professional cooperatives have experienced prosperous development and land stock cooperatives developed rapidly. Cooperation in land is flourishing. There are 2,182 land stock cooperatives in Sichuan, an increase of 93.8\% over last year; land pooled as shares reaches up to 33334 hectares, an increase of $89.7 \%$, and members with land pooled as shares reached 162,000 households, an increase of $152.9 \%$.

Development patterns of Sichuan farmers' professional cooperatives:-

Statistics of Sichuan Provincial Agricultural Department show that the numbers of farmers' professional cooperatives engaged in crop production, animal husbandry, forestry, fishery, service industry and other industries were respectively $21,809,15,232,3,669,2,028,2,593$ and 2,593, covering the entire industrial chain from 
production to processing and marketing. Moreover, cooperatives engaged in processing and marketing are developing rapidly, effectively enhancing value added of agricultural products. Figure 2 shows basic types of Sichuan farmers' professional cooperatives. It can be observed from the figure that crop production and animal husbandry are two major types of farmers' professional cooperatives, respectively accounting for $46 \%$ and $32.2 \%$ of total quantity of Sichuan farmers' professional cooperatives. Forestry and fishery also occupies certain proportions and there is still huge room for development of other types of farmers' professional cooperatives. Hence, it can be concluded that although the types of farmers' professional cooperative economic organizations in Sichuan are sound and diversified, farmers' professional cooperatives in such fields as services, processing, agricultural material supply, science and technology are few and are yet to be developed and promoted to make industry type of Sichuan farmers' professional cooperatives more extensive and industrial structure more reasonable.

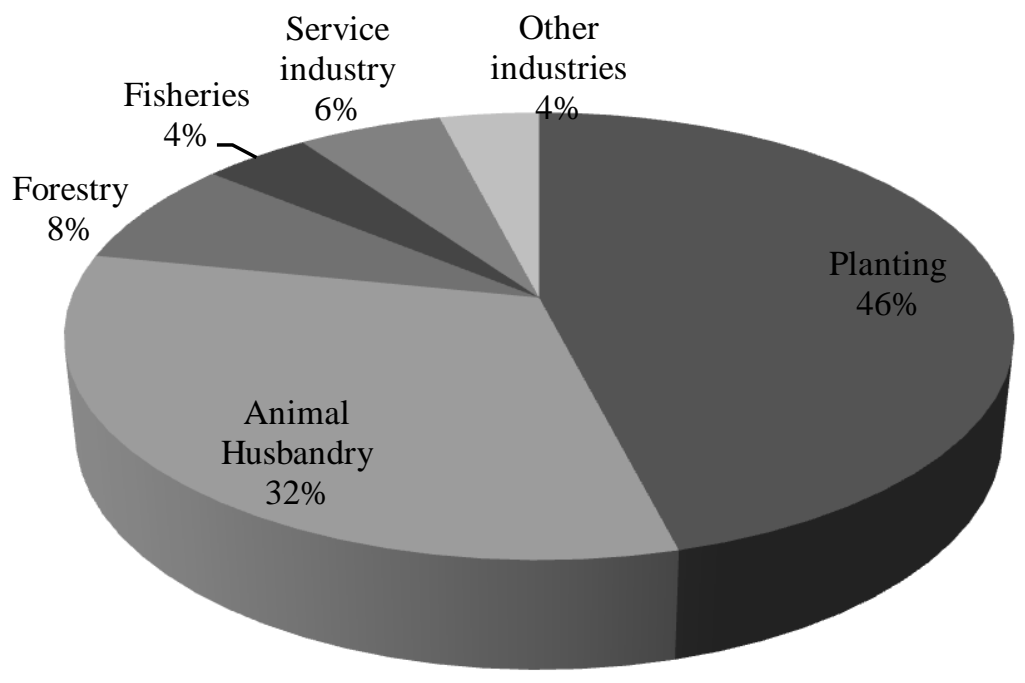

Figure 2:-Basic types of farmers' professional cooperatives in Sichuan Province in 2014

\section{General Features of Development of Sichuan Farmers' Professional Cooperatives:- \\ Continuously optimized industrial layout and constantly innovated management system:-}

In the process of development of farmers' professional cooperative economic organizations, they have gradually become effective driving forces promoting agricultural management system innovations, mobilized such production factors as land, capital and technology, facilitated innovations in rural investment and financing mechanisms and land management system and promoted moderate scale management of agriculture, adding vitality to modern agricultural development. Take Pengzhou City for instance. By making full use of the results of rural property right system reform, it has established professional agricultural resource management cooperatives and "land bank" oriented industrial development mechanism, mobilized land production factors, facilitated agricultural development and realized triple win of farmer households, owners and collective economic organizations.

\section{Increasingly obvious brand effect and increasing outstanding regional features:-}

Farmers' professional cooperative economic organizations have given full play to the role of a bridge to transform scientific achievements, actively sought cooperation with research institutes and scientific and technical personnel and introduced new technologies and new products in such ways as technical contracts, technology invested as capital stock and transfer of technology to promote and utilize scientific and technological achievements in agriculture and transform scientific achievements into actual productive forces. For example, citrus hybrid cooperatives in Pujiang County are actively building the citrus hybrid brand of the county and have formulated the first citrus hybrid plantation standard in the nation and applied for registration of the regional trademark of "Pujiang Citrus Hybrid". In 2010, Pujiang citrus hybrid won harm-free product certificate from Ministry of Agriculture and national "organic food certificate" and it is known as "Chinese famous fruit". In addition, plateau ecological wine grape, traditional Chinese medical materials, and animal husbandry in Ganzi and Aba Tibetan areas, unique dried delicacies from the mountains and under forest raising in Guangyuan and Bazhong as well as quality tea and tobacco products of Ya'an and Liangshan all have high brand effects. 
Enhanced overall agricultural productivity and constantly expanding scope of cooperation:-

Cooperation among farmers' cooperative organizations and between cooperative organizations and companies is gradually increasing and has developed from simple technical service cooperation to land, capital, labor force, technology shares and other various joint stock cooperation. In 2014, there were 4,906 land stock cooperatives and 10,708 fund investment cooperatives and their scope of cooperation ranged from traditional crop production and animal husbandry to tourism, agricultural machinery, plant protection, water and electricity, science and technology services and other regions, covering a wide range and various cooperation types. San'an vegetable professional cooperative in Yuechi County in Guang'an City has established four production bases, respectively, modern agricultural demonstration garden, indoor edible fungus production and seed production yard, seedling and seed selection base and seedling greenhouse base, by following requirements of development of modern agriculture, produces various top grade vegetables of over 30 categories all through the year and has realized the production value of RMB1.2 million and net profit of about RMB500,000 yuan.

Gradually extended agricultural industrial chain and ever increasing farmers' income:-

The greatest advantage of farmers' professional cooperative economic organizations is that they connect small production of thousands of households with the ever changing market, thus enhancing the organizational degree of farmers, promoting the status of farmers in market economy and increasing income of farmers, and also organically integrate production, processing, marketing, trade, industry and agriculture, increasing follow-up income of the farmers. For instance, Chengdu Shiling Poultry Cooperative has established the industrial chain from chicken farm to the market, developed a series of products with high technical contents, such as native egg, treasure egg and nutritious egg, and expanded the market from local to outside the province. The yield of eggs is increased to 22 million kilograms now from 2.4 million kilograms in the past and its output value has been raised to RMB105 million now from RMB15 million in the past. It has also driven the development of laying hen production of a total of 3,203 farmer households in surrounding region. In 2014, Sichuan agricultural product "three products, one geographical indication" certificates reached 2,750 and RMB8,803 yuan was the lowest per-capita income of the members, a year-on-year growth of $11.5 \%$.

Problems with Development of Sichuan Farmers' Professional Cooperative:-

In recent years, Sichuan farmers' professional cooperative economic organizations have developed steadily, with constantly enhanced overall strength and influence and prominent achievements in helping increasing farmers' income. However, according to requirements of balanced urban and rural development and leap from traditional agriculture to modern agriculture, there are certain problems that should not be ignored, mainly reflected in the following aspects.

Huge in quantity but poor in quality:-

By the end of 2014, the number of farmers' professional cooperatives in Sichuan reached 48,339 and the number of those with business registration certificates reached 47,329, an increase of 11,339 over last year. However, statistics of relevant departments indicate that average number of members of Sichuan farmers' professional cooperatives is about 70 people. The overall scale is small and benefit relations among members are not close enough. There are few cooperatives that properly play their roles, approximately 30\%. Most cooperatives still stay at the level of simple and superficial technical exchange and their activities and services are few. Simple services, insufficient market development, unsmooth channels and weak brand consciousness are particularly prominent problems. Consequently, it is difficult for them to play a greater role in unification of farmers, production, standards and brands, market expansion, interest binding and other aspects.

\section{Unbalanced regional development within the province:-}

Farmers' professional cooperatives in Sichuan assume the feature of more cooperatives in developed regions and few in mountainous and minority regions. Professional cooperatives in developed regions assume diversified development patterns and have entered the stage of upgrading and expansion, while those in certain mountainous and minority regions are still at the preliminary stage featured with poor organizational degree of farmers and cooperatives of small quantity, poor quality and small coverage. Take Liangshan Prefecture in Sichuan for instance. In 2014, the number of farmer households participating in farmers' professional cooperatives in the entire prefecture was 100,470 , accounting for only $9.63 \%$ of all farmer households in the prefecture and the number of farmers' professional cooperatives with business registration certificates was 718 , accounting for $30.41 \%$ of all farmers' professional cooperatives, far below the $82.31 \%$ of Sichuan Province. Industrial development is faced with "narrow scope and unbalanced" and huge regional gaps. Anning River Valley, Erbanshan Mountain Region and the 
abovementioned region are faced with regional development imbalance, production and marketing imbalance and crop production and animal husbandry imbalance. The number of farmers' professional cooperatives in Anning River Valley which is economically developed accounts for $88 \%$ of the total of such cooperatives in the entire prefecture and the number of farmers' professional cooperatives engaged in tobacco production and services accounts for $65 \%$ of the total; the number of farmers' professional cooperatives engaged in animal husbandry is only 230 while those engaged in agricultural product processing and marketing accounts for only $0.5 \%$ of the total.

Table 1 shows data of development conditions of farmers' professional cooperatives in certain regions in Sichuan in 2014. It can be observed from the table that there are huge differences in quantity of farmers' professional cooperatives, cooperative members and number of farmer households mobilized among various prefectures/cities and farmers' professional cooperatives assume the feature of well development, large scale and wide range of farmer households mobilized in developed regions and slow development, small scale and few farmer participants in mountainous and minority regions. For instance, Aba prefect, located in mountainous region in northwest Sichuan and backward in economic development, had farmers' professional cooperatives, members and number of farmer households mobilized of respectively 465, 28,000 households and 29,000 households in 2014. Nanchong, located in northeast Sichuan and a central city in northeast Sichuan, had 2,588 farmers' professional cooperatives, 540,000 households of members and 936,000 farmer households mobilized in 2014. Comparison and contrast show that there are significant discrepancies in development of farmers' professional cooperatives between different regions of Sichuan and there are also regional differences in cooperative members and number of farmer households mobilized. For instance, cooperative members of Bazhong and Luzhou in 2014 were both about 188,000 households, but the number of farmer households mobilized in Bazhong was 347,300 while that in Luzhou was 505,600 , which is related to influence and publicity of farmers' professional cooperatives in different regions.

Table 1:-Development of farmer professional cooperatives in various regions of Sichuan Province in 2014

\begin{tabular}{|l|c|c|c|}
\hline Cities(Stats) & $\begin{array}{l}\text { The Number of Farmer Specialized } \\
\text { Cooperatives }\end{array}$ & $\begin{array}{c}\text { Cooperative members } \\
\text { million households) }\end{array}$ & $\begin{array}{c}\text { Helpfarmers } \\
\text { (million households) }\end{array}$ \\
\hline Nanchong & 2588 & 54 & 93.6 \\
\hline Liangshan & 2361 & 10.2 & 35 \\
\hline Panzhihua & 556 & 1.08 & 4.2 \\
\hline Meishan & 1387 & 12 & 68 \\
\hline Mianyang & 1643 & 33.4 & 71 \\
\hline Dazhou & 1052 & 16.2 & 54 \\
\hline Bazhong & 1227 & 18.87 & 34.73 \\
\hline Chengdu & 2958 & 44.3 & 40.82 \\
\hline Guangyuan & 1234 & 8.37 & 36.64 \\
\hline Luzhou & 1357 & 18.76 & 50.56 \\
\hline Zigong & 743 & 6.8 & 48 \\
\hline Aba & 465 & 2.8 & 2.9 \\
\hline
\end{tabular}

Poor cooperative consciousness of farmers and dominant position not prominent:-

Interest binding among cooperative members is not close. Some farmers' professional cooperative organizations have not yet formed benefit and risk sharing mechanisms and cooperation between members is loose. There are few farmers' professional cooperatives practicing return of surplus and farmers' professional cooperatives and their members frequently assume the buyer-seller relationship featured with poor cooperative consciousness and weak attraction and cohesion. There are also farmers' professional cooperatives with family members as principal members and capital contributed by the family, but there is only one of all members who actually do the work while other members are simply nominal without truly participating in affairs of the cooperative; decision making and benefit distribution are determined by only one person, making it a "one-person cooperative". There are also "shell cooperatives", "nominal cooperatives" and "by-name cooperatives" in other regions.

Informal internal operation and unsound interest binding mechanism:-

Professional cooperative economic organizations are also faced with informal operation and unsound interest binding mechanism. Property right division among stakeholders of certain cooperative organizations is not clear; concerning democratic management, board of directors and supervisory mechanism of some farmers' professional cooperatives are superficial without playing any actual role and there is a lack of democratic management and proper supervision; in terms of designation, there are cooperative organizations with the designation of 
"association", "cooperative" and even "company", which is not consistent with norms of cooperative organizations. As for benefit distribution, there are various problems, including distribution not open and transparent, interest binding between cooperative organizations and farmer households not closed, lack of cohesion and attraction, etc. The cooperative-farmer interest binding mechanism of most farmers' professional cooperatives is unsound and insecure and the major forms are buyout and orders. Secondary distribution mechanism is not yet established, which is adverse to development and expansion of farmers' professional cooperatives. In terms of internal control, articles of association of some farmers' professional cooperatives are simply empty words and not binding and decisionmaking power and right of distribution of professional cooperative organizations are largely controlled by major members and initiators. There are also farmers' professional cooperative organizations controlled by rural cadres, leading enterprises and other minority mighty members, presenting the phenomena of "sole spokesperson" and "sole dominant shareholder".

\section{Policy Suggestions for Deepening Development of Sichuan Farmers' Professional Cooperatives:- Provide proper guidance services and improve development quality:-}

Give further play to guiding and comprehensive coordination role of agricultural departments and carefully arrange conferences on farmers' professional cooperative economic organization related work in Sichuan. Strengthen connection with relevant provincial departments to create favorable environment for development of farmers' professional cooperatives. Financial, industrial and commercial, tax and other departments should provide favorable services and further implement measures in such aspects as credit, taxation, land, financial funds and projects to support farmers' professional cooperatives. Relevant agricultural departments should strengthen business guidance, enhance development level of farmers' professional cooperative economic organizations and help farmers' professional cooperative economic organizations to improve their price, supply-demand and competitive mechanisms to improve their business quality and promote development of farmers' professional cooperatives.

\section{Learn from each other and strengthen efforts:-}

Guide development of farmers' professional cooperatives with the leading role of typical examples and formulate specific measures and work schemes based on actual regional and departmental work practices. Provide mountainous and economically undeveloped regions in Sichuan with experience and typical development patterns as well as favorable policies and encourage the farmers' professional cooperative economic organizations to actively carry out standard production, standard management, brand management and development pattern innovation, enhance uniform service and market development capabilities and gradually catch up with farmers' professional cooperatives in developed regions in Sichuan Province.

\section{Improve operational mechanism and strengthen policy guidance:-}

Formulate specific policy measures according to actual development conditions of farmers' professional cooperative organizations to support healthy and rapid development of the professional cooperative organizations. Strengthen financial fund support, encourage professional cooperative organizations to set up risk prevention funds and county (district, city), municipal and provincial finance should offer them with allowances to a certain proportion. Integrate state and provincial financial funds to form special support fund for development of professional cooperative organizations, strength support for financial fund interest subsidies and allocate part of financial funds supporting development of farmers' professional cooperative organizations to offer discount loans for projects with prominent results in helping increasing farmers' income. Moreover, link the development conditions of farmers' professional cooperative organizations with agricultural and rural work evaluation at all levels. Establish and improve objectives, responsibilities, work supervision and other systems for development of professional cooperative organizations.

\section{References:-}

1. WANG Y(2012). Predicament or Opportunity: Analysis on Condition of Farmer's Specialized Cooperatives [J].Chinese rural observation, 05: 41-46+53+95.

2. SUN Y F,Yu H P(2012). Cooperative willingness and influencing factors of farmers' professional cooperatives[J]. China's rural economy,06: 48-58+71.

3. HUANG S Y(2015). New type of farmers' professional co-operatives development problems and countermeasures[J].New West (Theoretical edition),10:59.

4. ZHENG D, WANG W(2012).Current situation, problems and policy suggestions on the development of Chinese farmers' professional cooperatives[J].Science and technology of China BBS, 02: 138-142.

5. LIAO S L, LIU JS(2014).Development status and suggestions of farmers' professional cooperatives in Yun He county [J]. Modern agricultural science and technology,07: 308-309. 
6. LAN Y, PENG L C and Luo J(2015). Farmer specialized cooperatives governance structure optimization strategy[J]. Cooperative economy and technology, 11: 5-8.

7. ZHANG L X, LIU XH(2015). External Environment of Agricultural Cooperatives in China's Western Region: Based on Survey of 71 Agricultural Cooperatives in Western China[J]. Agricultural Economics and Management, 03: 46-50.

8. ZHANG X S (2009).The development trend of farmers' professional cooperatives[J]. Management world, 05: 89-96.

9. HUO Z S (2015), Analysis on the new situation and development trend of farmers' professional cooperatives[J].Brand, 05: 63.

10. CHEN G R, SHENG Y P and LIU Y(2014). Establishment of Farmers' Cooperatives Performance Evaluation System Based on BSC[J]. Accounting Research, 02: 64-70+95.

11. ZHANGY(2011). Risk identification and management mechanism of farmers' Professional Cooperatives: a comparison of two basic cooperative organizations[J]. China's rural economy, 12: 14-24.

12. WAN BR(2010). Several issues on the current urgent need of farmers' professional cooperatives[J]. Agricultural economic problems, 10: 9-11.

13. ZHAOK(2011). A comparative study on the financing mode of Chinese farmers' professional cooperatives[J]. The rural economy, 05: 75-78.

14. Xu X C(2012).Analysis of Farmer Specialized Cooperatives: A Domestic Literature-based discussion[J]. China Rural Survey, 05: 2-12+94.

15. CUI BY(2015). Farmer Specialized Cooperatives: Mechanism employed and effect value of social capital[J]. Journal of China agricultural university, 06: 12.

16. GUO H D, LOU D, HU Z H, et al(2009). Analysis of factors affecting the growth of farmers' Professional Cooperatives -- Based on the investigation of some farmers' professional cooperatives in Zhejiang Province[J]. Rural economy in China, 08: 24-31.

17. HUANG Z H, GAO LY(2012). The realization degree and influencing factors of farmers' professional cooperative social service function[J]. Rural economy in China, 07: 4-16.

18. Brief report of Sichuan Provincial Department of Agriculture[EB/OL].

19. http://www.scagri.gov.cn/zwgk/nygk/201503/t20150309_332102.html, 2015-03-09. 